Poliak, M., Tomicova, J., Cheu, K., Fedorko, G., \& Poliakova, A. (2019). The Impact of the CMR Protocol on Carrier Competitiveness. Journal of Competitiveness, 11(4), 132-143. https://doi.org/10.7441/ joc.2019.04.09

\title{
THE IMPACT OF THE CMR PROTOCOL ON CARRIER COMPETITIVENESS
}

\section{- Milos Poliak, Jana Tomicova, Kelvin Cheu, Gabriel Fedorko, Adela Poliakova}

\begin{abstract}
In 1956, an important step was taken in international road freight transport. The CMR Convention, the main purpose of which was to unify the rules for the international transport of goods and thereby promote the development of international trade, was concluded. From a practical point of view, this is of great importance to both carriers and transporters. Similarly, this Convention also incorporates the most important document for the carriage of goods, i.e. the consignment note CMR. Since the adoption of the CMR Convention, the method of calculating the carrier liability has changed with the adoption of the Protocol to the CMR Convention. The Protocol changed the system for calculating liability from one based on the gold franc to a system based on special drawing rights. This protocol has not only changed the unit of constraint, but has also reduced the value of liability limitation for carriers. However, the protocol, which introduced a change in the carrier liability system, has not been accepted by all states. This disparity causes differences in liability and also in the competitiveness of carriers. The aim of this paper is to identify the impact of the adoption of the Protocol on the competitiveness of the carrier in each state which is party to the agreement.
\end{abstract}

Keywords: document, CMR, convention, contract, carriage, liability, competitiveness JEL Classification: R48, H40

Received: May, 2019

1st Revision: November, 2019

Accepted: November, 2019

\section{INTRODUCTION}

Developments in human society are closely linked to the exchange of goods and thus to the development of transport. Transport has become an important need for humanity and is also a prerequisite for the operation of international trade. Within the EU, road transport has gradually gained a dominant position, especially at the expense of railways. Reasons for this are many, but among the most important are the quality and density of the road network within the EU, along with flexibility, speed, convenience, adaptability and other advantages road transport brings (Kan et al., 2015; Poliak \& Poliaková, 2015). Goods may be transported across national borders on the basis of the conclusion of a transport contract only. The conclusion of a contract for car- 
riage for international shipping would be considerably more complicated if the Convention on the Contract for the International Carriage of Goods by Road (CMR Convention) had not been introduced (Defossez, 2013). Under these circumstances, the carrier would have to be familiar with the national regulations of all countries involved, and would be required to organize all transport agreements accordingly. Fortunately, in Geneva in 1956 the CMR Convention for carriers was agreed upon, the purpose of which is to standardize the conditions governing the contract for the carriage of goods in the cross-border transport of goods. The application of the rules contained in the CMR Convention applies to separate transport contracts only, not to forwarding or similar contracts. The particular contract of carriage shall be governed by the Convention only if all the conditions laid down in the Convention are fulfilled (Lamont-Black, 2016; Schelin, 2016). The consignment note CMR has an important role in the international transport of goods. The CMR demonstrates proof of the conclusion of a transport contract, and at the same time, it represents a proof of receipt of the shipment by the carrier. Since the adoption of the CMR Convention, the method of calculating the liability of the carrier introduced by the adoption of the Protocol to the CMR Convention has been modified, with the Protocol changing the system for calculating liability from gold franc to a system based on special drawing rights. However, this Protocol, which introduces a change in the carrier liability system, has not been accepted by all states. This causes differences in liability and also in the competitiveness among carriers (Radionov, 2016). In this article, we want to verify the hypothesis that the adopted CMR protocol has actually reduced the limitation of the carrier's liability. We also want to determine if this has had a positive impact on the competitiveness of carriers. For verification, we will use model examples applying the liability limitation provisions under the CMR Convention and the CMR Protocol.

\section{THEORETICAL BACKGROUND}

The conclusion of a contract for international carriage would be considerably more complicated for the carrier in the absence of the CMR Convention, as carriers would have to be familiar with all the national transport regulations of the various countries in which they would transport the goods. Differences in legislation across countries and their inconsistent interpretation would result in misunderstandings in the conclusion of contracts, including claims on the carrier. For that reason, the CMR Convention was concluded in Geneva on 19 May 1956 (Spanjaart, 2016). The basic purpose of this Convention is to unify the rules for international road transport, thereby promoting the development of international trade. From a practical point of view, this is very important to both carriers and transporters, because if such a convention did not exist, all matters concerning liability would be governed separately by different sets of national regulations. In 1978, a Protocol to the Convention regarding compensation for damages, was signed in Geneva in Article 23. In 2008, the Convention was supplemented by an additional Protocol, with the addendum initiating the electronic consignment note, i. e. CMR.

International carriage is considered to be that in which the place of loading is in a different country that that of the place of unloading. In order to apply the CMR Convention to the International Carriage of Goods, either the place of loading or the place of unloading must be in a state that is a signatory to the CMR Convention (Verheyen, 2016). Three exceptions exist in 
which it is not possible to conclude a transport contract under the CMR Convention, although these agreements deal with international carriage: the transport of postal items, dead persons and furniture removal. The main reason why these shipments cannot be transported under the CMR Convention is that the value of the shipment cannot be determined, therefore the carrier's liability cannot be calculated (Quigley, 2006).

The CMR Convention uniformly governs the accompanying documentation of transported consignments, the principles of liability of the carrier, as well as the procedure for applying damages claims. The CMR also defines the most important document in the international transport of goods, the consignment note CMR (Ferrer, 2006). This is an official document in a standardized form, and is usually written in two languages. The consignment note shall be made out in three original copies signed by the consignor and the carrier. The signatures may be printed or replaced by the stamp of the consignor and the carrier, that is unless this is contrary to the law of the state in which the consignment note is drawn up. The first copy (red form) of the consignment note shall be given to the consignor; this is proof to the consignor that the goods have been handed over to the carrier for carriage. The second blue letter is intended for the consignee of the goods to determine the amount of goods to be taken from the carrier. The third green letter, intended for the carrier, is also a document confirming that the goods have been handed over to the consignee. Unless proved to the contrary, the consignment note shall represent a credible proof of the conclusion and content of the contract of carriage and the taking over of the consignment by the carrier. If the consignment note does not contain any reservations regarding the carrier along with justification for the reservations, the legal presumption applies. It is assumed that the consignment and the packaging for transport were in good condition at the time of acceptance by the carrier, and that the number of packages along with their markings and numbers corresponded to the particulars contained in the consignment note (Bonnet, 2016). Each consignment note shall contain the following mandatory particulars:

- The place and date on which the consignment note was drawn up

- The name and address of the consignor

- The place and date of receipt of the consignment

- The destination of the consignment

- The name and address of the carrier

- The name and address of the consignee

- The nature of the goods carried and the type of packaging; for dangerous goods, their generally recognized designation

- The number of packages, their special markings and numbers

- The gross weight of the consignment or the quantity otherwise expressed

- Transport-related costs (expenditure incurred from the moment the contract is concluded until the moment when the consignment is delivered, for example, customs duty, ancillary charges) 
- Instructions necessary for customs or other official proceedings and an indication that the shipment is also subject to the provisions of this CMR Convention (Szymonik, 2013)

This Convention has been gradually ratified by individual European countries, but non-European countries are also contracting members. Currently, a total of 55 countries have signed the CMR Convention.

\subsection{Carrier's responsibility in the international road carriage}

In the event of loss or damage of the goods, the carrier must reimburse the owner for each kilogram of cargo the maximum specified amount. Thus, the carrier is not liable for the cargo in its full value. Such damage is in most cases covered by other insurance (insurance of goods during transport). The carrier's liability begins when the goods are taken over and ends when the goods are delivered to the recipient. The carrier is responsible for damaging or losing the shipment during shipment and also for exceeding the delivery time. A carrier under the provisions of the CMR Convention is obliged to compensate for the loss of the total or partial loss of the shipment that arises from the moment of its takeover to the transport until its issue; see Denes (2018). The refund is calculated from the value of the shipment at the place and time it is taken over for shipment. The value of the shipment is determined by the stock exchange price. If the stock exchange price is not available, then according to the current market price. If no stock exchange or normal market price is available, then the value of the shipment shall be determined according to the general value of the goods of the same nature and quality. The carrier is exempt from liability if the loss of the shipment, its damage or exceeding the delivery period was caused by the authorized person or by the authorized person's order. Furthermore, the carrier is exempted if the damage was not caused by the carrier's negligence, was caused by the nature of the consignment or by circumstances which the carrier could not prevent and whose consequences are not within control. (Sein \& Uusen-Nacke, 2010). The carrier shall be liable if, the vehicle for transport is in a defective condition or because of an unlawful act or neglect of the person whom the carrier could rent the vehicle or employees from. Taking into account the provisions of the CMR Convention, the carrier shall be exempt from liability if the loss or damage arises from a particular hazard associated with one or more of these circumstances:

a) If open vehicles without sails are used, but if such use has been agreed and noted in the consignment note;

b) In the case of missing packaging or defective packaging of the consignment, it may cause the consignment to be subject to loss or damage;

c) The handling, stowage, loading or unloading of the consignment by the consignor, the consignee or the persons acting on behalf of the consignor or the consignee;

d) The inherent nature of certain goods for which they are subject to total or partial loss or damage, in particular by fracture, rust, internal deterioration, desiccation, leakage, normal loss, insect or rodent action;

e) If the marks or the numbers of the individual packages are insufficient and incorrect;

f) Transport of live animals. 
Under the CMR Convention, the carrier's liability is determined in two ways. It depends on the data in the consignment note or in the transport contract. In the event that a consignment price or special delivery interest is indicated in the consignment note or in the transport contract (expressed in the relevant amount), the carrier is liable for the damage to the consignment or its loss up to the amount of its price / amount. If the price of the consignment or the special delivery interest is not specified in the consignment note or in the transport contract, the carrier's liability is subject to the provisions of the CMR Convention, Article 23 of the CMR Convention in particular (Stevens, 2004). Under Article 23 (3) of the CMR Convention, the liability of the road carrier is adjusted so that the compensation may not exceed 25 francs per kilogram of gross missing weight. Frank means a gold franc (GF), which has a weight of 10 / 31grams and a purity of 0.900 . If the shipment is damaged or lost, the carrier is liable for damage of up to a maximum of 25 francs per kilogram of damaged or lost goods. This liability limitation system is related to a certain amount of gold dating back to the Bretton Woods Agreement, when the world financial system relied on a stable gold price despite currency fluctuations expressed in the official gold parity. This value was declared by the members of the International Monetary Fund (IMF). In 1971, the Bretton Woods Agreement was abolished and the currencies no longer had a fixed gold exchange rate and the value of gold began to fluctuate freely in the markets. For this reason, there were already two gold values: the first one was the official rate and the second one the free market rate. The free market rate was significantly higher than the official rate and its height was constantly changing. The CMR Convention did not offer a solution to the problem of the value to be taken into account when calculating the value of the limit of commitment of 25 gold francs in national currency. Therefore, the Protocol in 1978 was adopted with the sole purpose of replacing the gold franc with a new Special Drawing Rights (SDR) defined by the IMF (Radionov, 2016). This eliminated the problem of calculating the value of gold for the states parties to the Protocol. This limitation of liability is currently in force in the eleven countries that have not ratified the CMR Protocol. The remaining countries have significantly reduced the liability of carriers because the gold franc has been replaced by SDR. The carrier is required to indemnify the owner of the goods transported in the amount of SDR 8.33 per kilogram of damaged, destroyed or lost goods. The particular value depends on the exchange rate of SDR and EUR. Its value is based on the values of 5 national currencies (U.S. dollar, euro, Japanese yen, Chinese renminbi and pound sterling). In addition, the carrier must also pay for the carriage charges, customs duties and other charges associated with transport. This value is covered by carrier liability insurance (Sker, 2003; Vukovic, 2013)

\section{RESEARCH OBJECTIVE, METHODOLOGY AND DATA}

The aim of the paper is to identify the impact of the CMR Protocol adoption on the competitiveness of carriers in individual countries. Competitiveness in this case is influenced by the amount of liability of the road carrier. In international road transport, liability can be limited by the adoption of the CMR Convention or the Protocol. For this reason, the contribution is based on an analysis of the contracting countries of the CMR Convention and the Protocol. As already mentioned, not all the states parties to the CMR Convention acceded to the CMR Protocol. Currently, 55 countries have ratified, acceded or succeed the CMR Convention. Individual countries 
that have acceded to the CMR are listed Table 1.The countries are ordered by the date of adoption of the CMR Convention. All countries of the European Union are the state parties to this Convention. In addition, the table also provides information about the countries that have signed the above-mentioned Protocol. The accession to the Protocol concerning the CMR Convention is not automatic; it does not follow from the status of the member state of the CMR Convention. In this case, up to 11 countries have not acceded to this Protocol. Among the countries not accepting it is one EU country - Bulgaria. Most of the countries that acceded to the Convention after 1978 either adopted the protocol on the same date or have not yet adopted it. Croatia was the last country to accede to this Protocol on 31 January 2017.

Tab. 1 - Contracting parties of the CMR Convention and the Protocol CMR. Source: own research

\begin{tabular}{|l|l|}
\hline Convention CMR and Protocol CMR & Only Convention CMR \\
\hline France, Austria & Bulgaria \\
Netherlands, Germany & Bosnia and Herzegovina \\
Italy, Poland & Morocco \\
Belgium, Luxembourg & Kazakhstan \\
Denmark, United Kingdom of Great Britain & Tajikistan \\
and Northern Ireland & Serbia \\
Norway, Sweden & Mongolia \\
Portugal, Switzerland & Azerbaijan \\
Hungary, Romania & Montenegro \\
Finland, Spain & Ukraine \\
Greece, Russian Federation & Syrian Arab Republic \\
Ireland, Slovenia & \\
Croatia, Lithuania & \\
Belarus, Estonia & \\
Republic of Moldova, Slovakia & \\
Czech Republic, Latvia & \\
Tunisia, Turkey & \\
Uzbekistan, Turkmenistan & \\
North Macedonia, Kyrgyzstan & \\
Cyprus, Lebanon & \\
Armenia, Albania & \\
\hline Malta, Jordan & \\
\hline
\end{tabular}


As shown in the table, not all the countries have acceded to the Protocol, which results in different restrictions of the carrier's liability for damaged, destroyed or lost goods in individual countries. However, this also has an impact on the competitiveness of the carrier. The Convention and the Protocol set an upper limit for limiting the carrier is liability. The liability value depends on the unit (GF or SDR), the gross weight of the goods and the current exchange rate. The calculations of carrier's liability for $1 \mathrm{~kg}$ of gross weight of goods are given in Table 2 . In the case of the CMR Convention, two carrier liability calculations are provided. The first one is based on the last defined GF official rate of 1978; the second one is based on the current gold market rate. Exchange rates and the value of gold are expressed as of 29 March 2019.

Tab. 2 - Calculation of the carrier's maximum liability for $1 \mathrm{~kg}$ of gross weight. Source: own research

\begin{tabular}{|c|c|c|}
\hline $\begin{array}{l}\text { Liability of the carrier accord- } \\
\text { ing to CMR Convention } 1956\end{array}$ & $\begin{array}{l}\text { Liability of the carrier accord- } \\
\text { ing to CMR Convention } 1956\end{array}$ & $\begin{array}{l}\text { Liability of the carrier ac- } \\
\text { cording to Protocol CMR }\end{array}$ \\
\hline Restriction Unit: GF & Restriction Unit: GF & Restriction Unit: SDR \\
\hline Limitation: $25 \mathrm{GF}$ & Limitation: $25 \mathrm{GF}$ & Limitation: 8.33 SDR \\
\hline $1 \mathrm{GF}=1.94149 \mathrm{USD}$ & $1 \mathrm{GF}=10 / 31 \mathrm{~g}$ fineness 900 & $1 \mathrm{SDR}=1.235650 €$ \\
\hline $1 \mathrm{USD}=0.8901 €$ & $=0.323 \mathrm{~g}$ & $8,33 \mathrm{SDR}=8.33 \times 1.23565$ \\
\hline $1 \mathrm{GF}=1.94149 \times 0.8901=$ & $1 \mathrm{~g}$ gold $=34.05 € / \mathrm{g}$ & $=10.29 €$ \\
\hline $1.73 €$ & $25 \mathrm{GF}=25 \times 0.323 \times 34.05=$ & \\
\hline $25 \mathrm{GF}=25 \times 1.73=43.25 €$ & $274.95 €$ & \\
\hline $\begin{array}{l}\text { Maximum responsibility for } 1 \\
\operatorname{kg} 43.25 €\end{array}$ & $\begin{array}{l}\text { Maximum responsibility for } 1 \\
\operatorname{kg} 274.95 €\end{array}$ & $\begin{array}{l}\text { Maximum responsibility } \\
\text { for } 1 \mathrm{~kg} 10.29 €\end{array}$ \\
\hline
\end{tabular}

\section{RESULTS AND DISCUSSION}

The following model examples illustrate the importance of accepting the Protocol from the carrier's perspective. In these examples, the weight of the damaged goods is identical, only the value of the goods is changed.

Model Example 1 - Carrier's liability for damage of 10 tons of goods with a value of 100,000€.

Responsibility under the CMR Convention, the rate of $1978=10,000 \times 43.25=432,500 €$ Responsibility under the CMR Convention, the gold rate $=10,000 \times 274.95=2,749,500 €$

Responsibility under the Protocol CMR $=10,000 \times 10.29=102,900 €$

In the case of damage to goods worth $100,000 €$, there is no difference in the perception of limitation of liability of the carrier, because the specified maximum liability under the Protocol the Convention as well as exceeds the total value of the goods. In this case, the carrier is only liable up to the total value of the goods, thus up to $100,000 €$. If the value of the goods is low (about 10 $€ / \mathrm{kg}$ ) the carrier's liability is equal, even if the protocol was not accepted. 
Model Example 2 - Carrier's liability for damage of 10 tons of goods with a value of 150,000€.

Should such a shipment be damaged, the carrier would only be liable under the CMR Protocol up to the limit of its liability limit of $102,900 €$. If the liability is established under the CMR Convention, the carrier corresponds to the full value of the shipment, i.e. up to $150,000 €$.

Model Example 3 - Carrier's liability for damage of 10 tons of goods with a value of 250,000€.

In this case, the carrier's liability is already significantly changed. The countries where the protocol now has been adopted had previously limited the carrier's liability to $102,900 €$. In other countries, the carrier is responsible for the total value of the goods $(250,000 €)$. This is because the limit of liability according to the CMR Convention, which is gross weight $25 \mathrm{GF} / \mathrm{kg}$ of goods, is raised to $432,500 €$. The carrier would have to transport goods with a value of over $432,500 €$ in order to limit liability and this would not correspond to the total value of the goods. By adopting the protocol, the carrier's liability was reduced by almost $150,000 €$ in this example.

Model Example 4 - Carrier's liability for damage of 10 tons of goods with a value of 400,000€.

The countries in which the Protocol has been adopted have significantly affected the liability of their carriers. In the event of damage to a shipment worth $400,000 €$, such carriers will only be liable for up to $102,900 €$. It would be advisable for the customer to have the shipment insured in case of damage. Under the CMR Convention, liability is limited to $432,500 €$, which is a higher value than the value of the shipment itself. In this case, the carrier is liable for $400,000 €$ per shipment.

Model Example 5 - Carrier's liability for damage of 10 tons of goods with a value of 500,000€.

By adopting the protocol, the carrier is only liable up to $102,900 €$. In the countries where the Protocol has not been adopted, the carrier is no longer responsible for the total value of the goods. Due to its limit of $25 \mathrm{GF}$, the carrier is responsible for damaged goods worth up to $432,500 €$. In this case, the adoption of the Protocol reduced the carrier's liability by almost $330,000 €$, which is already a significant decrease in the liability for carriers. If we exchange the value of $25 \mathrm{GF}$ to euros according to the actual market values of gold, we determine that the carrier would be liable up to $2,749,500 €$. Obviously, only in rare cases would the actual value of the goods be higher than this amount.

The right to limit the carrier's liability for the goods ensures the economic sustainability of the transport company. This is because in case of damage, the carrier is obliged to pay only a certain maximum amount (shown in the model examples). The carrier may insure the shipment for this amount. An insurance limit of 8.33 SDR is standard and acceptable on the market. This is because this figure is in line with the provisions of the CMR Protocol to limit the liability of the carrier to this amount. Thus this type of insurance covers the needs of carriers in all cases in which they may invoke the right to limit their liability, but only if the contract of carriage is governed by the law of the contracting countries of the Protocol. In the countries where the 25 GF limit applies, however, this type of insurance is not sufficient. In the case of this type of insurance contract, approximately $11 €$ per kg of goods will be covered. The carrier is solely liable for the remaining amount up to the limit of liability or the total value of the goods. If the insurer covers only part of the damage under the terms of the policy, the carrier is responsible for the 
remaining amount. This creates problems associated with the survival of the business. It should be pointed out that if the carrier needs to insure the liability at a higher value, the costs associated with the conclusion of the insurance contract also increase.

Thus if the insurance coverage is in accordance with the limits of liability and the carrier has the right to limit its liability and has not lost these rights from liability insurance, the insurer shall bear all economic costs related to the damage incurred. In this case, the economic interests of the carrier remain wholly intact. It can therefore be said that limiting the liability of the carrier directly contributes to increasing the competitiveness of the carrier, and thus to gaining a superior market position of the undertaking in that country. Unless otherwise agreed in the insurance policy, the insurance is agreed upon with the carrier's participation regarding damage. Participation is a contractually agreed amount by which the insured (carrier) participates in a liability resulting from an insurance policy; participation is deducted from the total amount of damages to which the victim has a claim; and participation can be determined in the insurance contract by a fixed amount, a percentage, or a combination thereof. The following figure shows the responsibilities of each contracting party for the damaged goods if the carrier's participation regarding damage is $10 \%$. The depiction is based on the above-mentioned model examples.

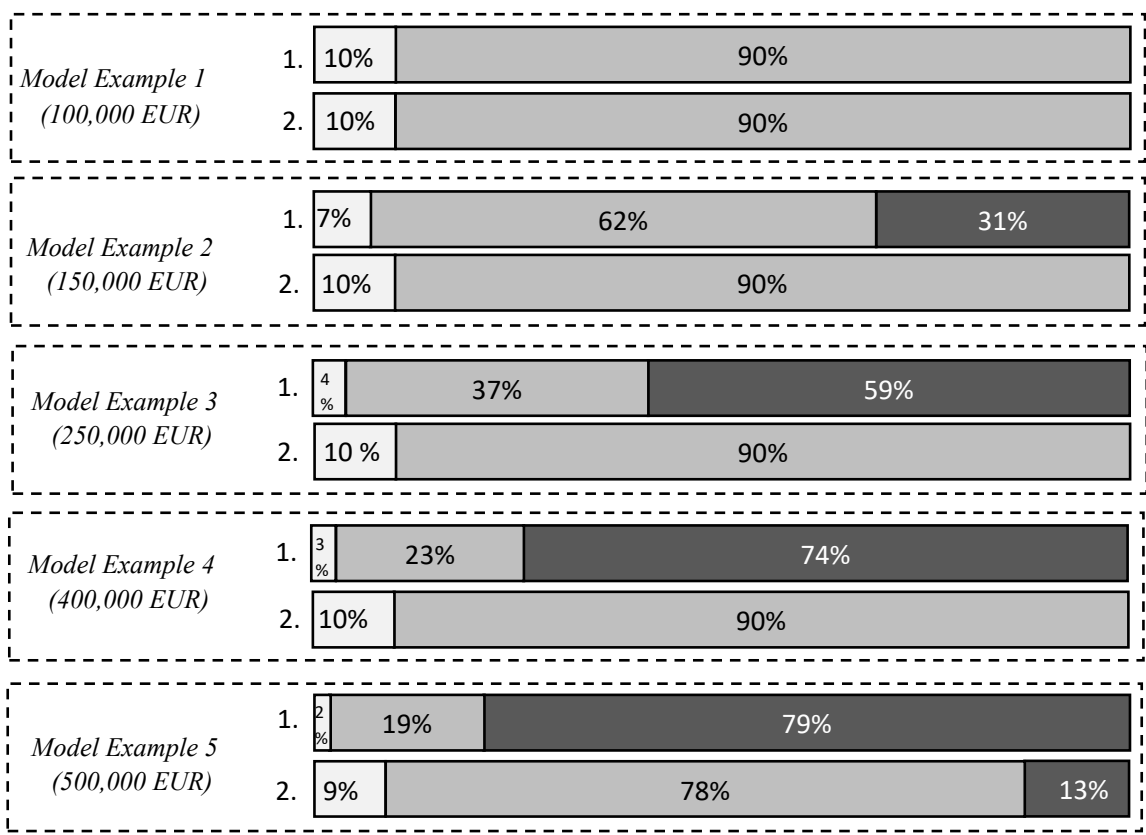

1. Protocol CMR $\quad 2 . \quad$ CMR Convention $\square$ Carrier $\square$ Insurer $\square$ Receiver

Fig. 1 - Share of the carrier's liability, the insurer and the receiver on the damaged goods. Source: own research

It is assumed that carriers have an insurance contract for a particular insurance sum, i.e. an amount related to their liability limitation. In the case of a carrier governed by the provisions 
of the CMR Convention, an insurance contract must be concluded for a higher insurance sum, which of course has an impact on liability insurance costs. In the case of goods of less value, the individual contracting parties bear the same costs. There are significant differences in costs for the contracting parties in the model example 3. If the carriers comply with the terms of the Protocol, they have limited their liability for damage and bear the costs of about $41 \%$ of the value of the goods, of which $37 \%$ must be paid by the insurer. The receiver pays for the remaining costs. In this case, it is advisable for the receiver to insure the shipment. Under the Convention, the carrier must pay the total value of the goods. The carrier has to pay $10 \%$ of the value of the goods, the rest $(90 \%)$ is paid by the insurer. In the last model example, the carrier's liability is already limited in both cases. One carrier pays $2 \%$ of the value of the goods (according to the Protocol) and another carrier pays up to $9 \%$ of the value (according to the Convention). In this case, it is also advisable for the receiver to insure the shipment.

The different conditions in different countries in terms of accession to the CMR Protocol significantly change the conditions for carrying out transport and conditions regarding the competitiveness of carriers. Carriers from countries that have ratified the CMR Protocol have a significantly lower responsibility as compared to carriers from the countries that have not ratified the protocol. However, this also changes the liability insurance conditions and also affects the liability insurance costs. Different market conditions for carriers transporting goods in the EU common market cause a distortion of the competitive environment.

\section{CONCLUSION}

The CMR Convention, which regulates international road freight transport contracts, is currently the most essential tool for distributing responsibility between the carrier and the transport customer. By adopting the Convention, carriers limit their liability, with this limitation based on a GF unit of a value dependent on the fixed value of gold. At a later time, because of problems with two different gold market values, a protocol was adopted to resolve this problem. The value of responsibility now no longer depended on the value of gold, but on the SDR, i.e. a value on which on 5 national currencies are based on at present. The accession to the Protocol is not automatic, thus there are countries that have adopted the CMR Convention but have not adopted the Protocol. Currently, 1 out of the 5 state parties to the Convention have not acceded to the Protocol. It is important to note that all EU countries are contracting parties of the Protocol except for Bulgaria. This is very important given the fact that some of the main corridors of the trans-European transport network cross this country. This may result in disproportionate liability, which may affect the commercial interests of all parties involved in the international carriage of goods. Given that this country has not acceded to the agreement, a higher level of responsibility for the carrier shipping through Bulgaria is in effect is the case than with the other EU Member States. This affects the conditions of liability insurance as well as liability insurance costs. It is evident from the model examples that after the protocol was adopted these countries significantly limited their carriers' liability and thereby increased their competitiveness. Based on our research, we can confirm the validity of the hypothesis. The countries that have not adopted the Protocol have approximately 4.5 times more responsibility than the countries where the Protocol has been accepted. Responsibility would be much higher if the actual value of gold were the basis on which liability was calculated. 


\section{Acknowledgements}

This contribution was supported with the support of the Ministry of Education of the Slovak Republic, VEGA no. 1/0143/17 POLIAK, M.: Increasing the competitiveness of Slovak carriers providing road transport services in the common market of the European Union.

\section{References}

1. Bonnet, J. C. (2016). CMR - International Convention of Geneva relating to the Contract for the International carriage of goods by Road 19 May 1956. Uniform Law Review, 21 (4), 418-420. https://doi.org/10.1093/ulr/unw052

2. Calculated Scrap Gold Value. Gold Calculator for Scrap, http://www.goldcalc.com/scrap_ gold_value.php, March 29, 2019

3. Defossez, D. (2016). CMR: what if the courts got it wrong? Uniform Law Review, 21 (1), 75-100.

4. Denes, A. (2018). Considerations on the contract for the international carriage of goods by road. Revista De La Facultad De Derecho, 44 (1), 253-285. https://doi.org/10.22187/ rfd2018n44a9

5. Ferrer, J. C. (2006). The Cmr Convention - A Pillar of International Carriage of Goods by Road. Uniform Law Review, 11 (3), 517-521. https://doi.org/10.1093/ulr/11.3.517

6. Kan, S. M., Kurmangaliyeva S. G. \& Plekhanov, P. A. (2015). Some aspects of methods elicitation economic expediency cargo carriage the different types of transport. Bulletin of the National Academy of Sciences of the Republic of Kazakhstan, 6 (10), 66-70.

7. Lamont-Black, S. (2016). The UK Supreme Court on jurisdiction over successive CMR Convention carriers and European Union rules. Uniform Law Review, 21 (4), 487-509. https://doi.org/10.1093/ulr/unw041

8. Poliak, M., \& Poliaková A. (2015). Relation of social legislation in road transport on driver's work quality. Communications in Computer and Information Science, 531 (10), 300-310. https://doi. org/10.1007/978-3-319-24577-5_30

9. Quigley, I.(2006). Freight Carrier`s Liability under the CMR convention 1956. Acta Oeconomica Pragensia, 14(4), 41-45.

10. Radionov, N. (2016). Limitation of liability right in road freight carriage in Croatia: an extinct institute. Uniform Law Review, 21 (4), 457-468. https://doi.org/10.1093/ulr/unw035

11. Schelin, J. (2016). CMR Convention in a law and economics perspective. Uniform Law Review, 21 (4), 434-440. https://doi.org/10.1093/ulr/unw036

12. International Monetary Fund. Retrieved from https://www.imf.org/external/np/fin/data/ rms_five.aspx

13. Sein, K., \& Uusen-Nacke, T. (2010). Contracts of Carriage: Legislation and Case Law in Estonia. Review of Central and East European Law, 35 (4) 341-368. https://doi.org/10.1163/157 $303510 X 12650378240511$

14. Sker, T. (2003). Analysis of Road Carriers Liability for Robbery of Cargo According to CMR Convention. Promet-Traffic-Traffico, 15 (6), 371-374. https://doi.org/10.7307/ptt. v15i6.903 
15. Spanjaart, M. (2016). The successive carrier: a relic from the past. Uniform Law Review, 21 (4), 522-532. https://doi.org/10.1093/ulr/unw038

16. Stevens, F. (2004). Towards a liability regime for road carriage the European experience: The CMR convention. 23rd Annual Southern African Transport Conference, SATC 2004: Getting Recognition for the Importance of Transport 2004, 706-712.

17. Szymonik, A. (2014). International logistics. Lodz, IL: Lodz University of Technology

18. United Nations, Convention on the Contract for the International Carriage of Goods by Road, Geneva, 16 May 1956

19. Verheyen, W. (2016). National judges as gatekeepers to the CMR Convention. Uniform Law Review, 21 (4), 441-456. https://doi.org/10.1093/ulr/unw039

20. Vukovic, A. (2013). Units of Account in International and Domestic Transport Law. Nase More, 60 (1-2), 11-16.

\section{Contact information}

prof. Ing. Milos Poliak, PhD.

University of Žilina

Faculty of Operation and Economics of Transport and Communications

Department of Road and Urban Transport

Univerzitna 1, 01026 Žilina,

Slovak Republic

E-mail:milos.poliak@,fpedas.uniza.sk

ORCID: 0000-0002-9149-2439

Ing. Jana Tomicova

University of Žilina

Faculty of Operation and Economics of Transport and Communications

Department of Road and Urban Transport

Univerzitna 1, 01026 Žilina,

Slovak Republic

E-mail:jana.tomicova@fpedas.uniza.sk

ORCID: 0000-0002-0159-6411

Kelvin Cheu, Ph.D., P.E., F.ASCE, SM.IEEE

University of Texas

Faculty of Engineering

Department of Civil Engineering

Engineering Building, Room A-208, $500 \mathrm{~W}$ Uni-

versity, El Paso, Texas 79968,

USA

E-mail:rchen@utep.edu

ORCID: 0000-0002-0791-2972 prof. Ing. Gabriel Fedorko, PhD.

Technical University of Košice

Faculty of Mining, Ecology, Process Control and

Geotechnologies

Institute of Logistics and Transport

Park Komenského 14, 04200 Košice,

Slovak Republic

E-mail:gabriel.fedorko@tuke.sk

ORCID: 0000-0002-5187-5283

Ing. Adela Poliakova, PhD., EUR ING

University of Žilina

Faculty of Operation and Economics of Transport and

\section{Communications}

Department of Economics

Univerzitna 1, 01026 Žilina,

Slovak Republic

E-mail:adela.poliakova@fpedas.uniza.sk.

ORCID: 0000-0002-9971-9589 